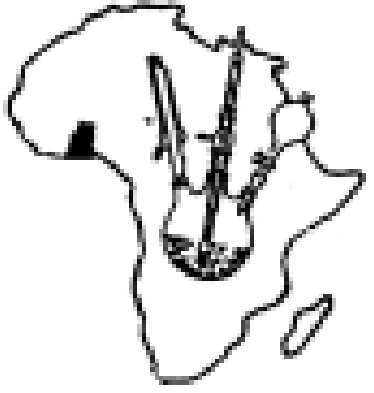

- to cooperate with other international bodies that pursue aims and objectives similar to those of AAPAC

- to promote mutually beneficial interdependent links between industry and other entrepreneurial bodies on one hand and research institutes, including universities, on the other

AAPAC is committed to bring together African chemists, who have so much in common through the subject of chemistry, through the problems of teaching chemistry in Africa, and through industrial and other problems that have chemical solutions.

AAPAC is currently developing a database of chem- istry in Africa comprising the following three parts:

- chemical science departments and the staff of these departments in the universities of Africa

- chemically related industries in Africa

- national chemical societies of Africa

For more information about AAPAC and/or to participate in developing the database by completing a questionnaire, contact Prof. Trevor M. Letcher (President of AAPAC and Titular Member of the IUPAC Commission on Thermodynamics, I.2, Tel.: +27 31260 2616; Fax: +27 31260 3091; E-mail: letcher@ che.und.ac.za) or Dr. Bice Susan Martincigh (Secretary-General of AAPAC and South African National Representative on the IUPAC Commission on Photochemistry, III.3, Tel.: +27 31260 1394; Fax: +27 31 260 3091; E-mail: martinci@scifs1.und.ac.za), School of Pure and Applied Chemistry, University of Natal, Durban 4041, South Africa.

\title{
New Books and Publications
}

\section{New Books from IUPAC}

\section{In Situ Monitoring of Aquatic Systems: Chemical Analysis and Speciation. Vol. 6, IUPAC Series on Analytical and Physical Chemistry of Environmental Systems (Series Editors: Jacques Buffle and Herman P. van Leeuwen). Edited by Jacques Buffle and George Horvai. John Wiley \& Sons Ltd. (2000), pp. xviii + 1-623. ISBN 0-471- 48979-4.}

\section{Contents}

General Concepts; Electrochemical and Optical Oxygen Microsensors for In Situ Measurements; Sensors for In Situ $\mathrm{pH}$ and $\mathrm{pCO}_{2}$ Measurements in Seawater and at the Sediment-Water Interface; Sensors for In Situ Analysis of Sulfide in Aquatic Systems; Potentiometric Microsensors for In Situ Measurements in Aquatic Environments; Biosensors for Analysis of Water, Sludge, and Sediments with Emphasis on Microscale Biosensors; Continuous Flow Techniques for On-Site and In Situ Measurements of Metals and Nutrients in Sea Water; Dynamic Aspects of In Situ Speciation Processes and Techniques; In Situ Voltammetry: Concepts and Practice for Trace Analysis and Speciation; Permeation Liquid Membranes for Field Analysis and Speciation of Trace Compounds in Waters; Dialysis, DET, and DGT: In Situ Diffusional Techniques for Studying Water, Sediments, and Soils; Microtechnology for the Development of In Situ Mi- croanalytical Systems

To enable efficient interpretation of the functioning of ecosystems such as lakes, oceans, or ground water, the recording of large data sets is essential, in order to take into account natural spatial and temporal variations correctly. This undertaking requires the use of a network of in situ or on-field sensors or analytical devices, for continuous, real-time monitoring of major, minor, and trace components, simultaneously at a large number of locations in the ecosystem, and at various depths in the water columns or ground water. Such a huge number of analyses is not feasible by using the classical approach based on sample collection, storage, and transportation, followed by sample handling in the laboratory. Robust sensors and instruments for automatic in situ or on-site measurements should thus be developed. This approach is required not only for the reason of cost effectiveness, but also for scientific reasons. Indeed, determinations of minor and trace inorganic and organic compounds have become more and more important for water quality assessment. Classical analyses of these compounds, however, are often prone to many artifacts that can only be overcome by in situ measurements, avoiding the sampling step.

This book includes the most important in situ sensors and analytical systems. Chapter 1 discusses general concepts that should be considered for the development of any type of sensor, in order to get reliable and environmentally relevant information. It also helps the reader to place the various chapters in perspective to each other, inside a common frame. The next four 
chapters deal with sensors for in situ measurements of major components: $\mathrm{O}_{2}$ (Chapter 2), $\mathrm{pH}$ and $\mathrm{CO}_{2}$ (Chapter 3), $\mathrm{S}^{2-}$ (Chapter 4), and $\mathrm{Ca}^{2+}$ and $\mathrm{N}$ species (Chapter 5). Chapters 6, 7, and 9-11 deal with sensors and analytical systems for minor or trace organic or inorganic components. In these cases, the signal most often depends on the speciation of the test analyte. All these chapters thus discuss speciation aspects relevant to each technique. Chapter 8 is specifically devoted to the physicochemical principles needed to understand how dynamic chemical equilibria, such as metal complexation, affect the signal of analytical devices based on flux measurements. Because most trace compound determinations are based on such flux measurements, we have found it important that a rigorous formulation of these general physicochemical concepts, and some examples of their applications to a few sensor types, be described in a specific chapter.

Finally, the book ends with the existing microtechniques that could be used for the fabrication of in situ sensors or microanalytical systems. Although very few complete analytical systems have yet been built based on this technology, and none of them for environmental application, it is clear that the fabrication of at least key components (such as microelectrodes, microreactors, etc.) of in situ analytical devices should thus greatly profit from microtechnologies. The main purpose of this chapter is to stimulate ideas for new microsensor or microanalytical system construction, by using the concepts of microsensors described in Chapters 2-6, which were built with more classical technologies.

This book should provide researchers interested in the development of in situ sensors and analytical systems with the appropriate updated literature and critically evaluated information. However, we hope that it will be even more helpful to laboratories in charge of water quality assessment, by providing them with updated information on existing sensors and analytical systems, their present capabilities, and the expected future developments. In most cases, either detailed technical information is given or the corresponding literature is cited, which should help any interested scientist to start using these analytical devices in an appropriate manner. Thanks to the theoretical background discussed in particular for methods related to speciation, correct interpretation of the data should also be made easier, even for the nonspecialist.

\section{Jacques Buffle, University of Geneva, Geneva, Switzerland George Horvai, Technical University of Budapest, Budapest, Hungary}

Note: For the Macromolecular Symposia volumes listed below, the Table of Contents and Preface are available on the IUPAC web site at http://www.iupac.org/ publications/macro/2000/index.html. See also http:// www.wiley-vch.de/vch/journals/2265/index.html and http://www.interscience.wiley.com.

Macromolecular Symposia, Vol. 156:

Macromolecule-Metal Complexes (MMC-8). Symposium Editor, Eishun Tsuchida; Coeditors, Masao Kaneko and Teruyuki Komatsu; Editor, I. Meisel; Associate Editor, S. Spiegel; Assistant Editors, H. Beattie and C. S. Kniep. Published by Wiley-VCH, July 2000, pp. 1-284. ISBN 3-52730135-6 (ISSN 1022-1360).

This issue contains plenary and invited lectures delivered at the $8^{\text {th }}$ IUPAC International Symposium on Macromolecule-Metal Complexes (MMC-8 Tokyo), which was held at Ibuka Memorial Hall, the International Conference Center of Waseda University, Tokyo, Japan, 5-9 September 1999 (see conference report by Prof. Kazuyuki Horie published in Chemistry International in March 2000, Vol. 22, No. 2, pp. 41-42).

The field of MMC is now receiving much attention not only in chemistry and macromolecular science, but also as a frontier material system with numerous molecular functions. Since the first symposium, MMC-1, that was held in Beijing in 1985, the biennial IUPAC MMC symposia have been providing a special opportunity for scientists in this research field to meet each other and to become aware of the most recent progress in MMC.

Around 280 delegates from 20 different countries attended MMC-8. In addition to 8 plenary and 27 invited lectures, contributed papers were presented in 6 oral contributions and 100 posters. The well-organized program and outstanding facilities of the conference center provided excellent possibilities for extended discussions among the delegates. The theme of this symposium focused on the role of MMC in the recent development of macromolecular sciences and technologies. The latest results in the fundamental part, which are related to multielectron transfers, supramolecules, dendrimers, and molecular recognition, and in advanced technologies, such as photoenergy devices, sensors, catalysis, electronics, and biomaterials, were widely discussed by a variety of scientists. Furthermore, the "priority session" took place with a strong involvement of industrial participants. This session focused on secondary batteries and portable fuel cells, which is a growing superior technology related to MMC science, especially in Japan.

One of the factors that made this symposium successful was the large number and the positive attitude of the younger participants who will bear the next generation. On the other hand, MMC prizes were awarded 
to the eight representative senior scientists who contributed significantly to the development of MMC. It is hoped that delegates left MMC-8 with new knowledge and new friendships that will lead to many contributions for further progress in this research field in the forthcoming century.

The $9^{\text {th }}$ IUPAC International Symposium on Macromolecule-Metal Complexes (MMC-9) will be held in Brooklyn, New York, USA, 19-23 August 2001. Finally, the editor would like to thank all who have contributed to this symposium and express particular appreciation to them.

Prof. Eishun Tsuchida

Department of Polymer Chemistry, ARISE Waseda University

Tokyo, Japan

Macromolecular Symposia, Vol. 157: Ionic Polymerization. Symposium Editor, Shiro Kobayashi; Editor, I. Meisel; Associate Editor, S. Spiegel; Assistant Editors, H. Beattie and C. S. Kniep. Published by Wiley-VCH, July 2000, pp. 1257. ISBN 3-527-30136-4 (ISSN 1022-1360).

The IUPAC International Symposium on Ionic Polymerization (IP'99) was held 19-23 July 1999 in Kyoto, Japan (see conference report by Prof. Stanislaw Penczek published in Chemistry International in May 2000, Vol. 22, No. 3, pp. 79-80). The symposium was also sponsored by the Chemical Society of Japan; the Society of Polymer Science, Japan; the Society of Synthetic Organic Chemistry, Japan; and the Japan Chemical Innovation Institute. IP'99 is regarded as the third symposium in the series of International Symposia on Ionic Polymerization, following up the successful symposia in Istanbul (1995) and in Paris (1997).

The symposium aimed to bring together scientists and engineers from all over the world who are interested in ionic polymerization and related areas and to promote research development in these fields by an exchange of information and stimulating new ideas. The research area covered in this symposium was directed toward the traditional field of cationic, anionic, and ringopening polymerizations, as well as more broadly to polymer synthesis, including radical polymerization, metal-catalyzed polymerization, polycondensation, enzymatic polymerization, and new polymer architecture.

Approximately 260 active participants from 14 countries attended the symposium. A total of 94 oral reports, including invited lectures, were presented in two parallel sessions, and 61 posters were also presented. The presentations were of high quality and at the cutting edge of science and technology in these fields. Very vivid and excellent discussions took place during and after the scientific program, definitely contributing to the realization of the purpose of this symposium. This special issue of Macromolecular Symposia covers the papers from invited lectures, which will help scientists and engineers to find the future direction in ionic polymerization, as well as in other important fields in polymer synthesis.

The organization of this symposium was made possible with the help and collaboration of all the Committee and Board members. We deeply thank these people for their big effort. Our sincere thanks go to the following corporations for their support: Ajinomoto Co., Inc.; Asahi Chemical Industry Co., Ltd.; Asahi Glass Co.; Daicel Chemical Industries, Ltd.; Daikin Industries, Ltd.; Denki Kagaku Kogyo Kabushiki Kaisha; DuPont Kabushiki Kaisha; Harima Chemicals, Inc.; Hitachi Chemical Co., Ltd.; Japan Chemical Innovation Institute; Japan PMC Corporation; JSR Corporation; Kaneka Corporation; Kuraray Co., Ltd.; Lion Corporation; Mitsubishi Rayon Co., Ltd.; Mitsui Chemicals, Inc.; Nippon Zeon Co., Ltd.; Nissei Sangyo Co., Ltd.; Polyplastics Co., Ltd.; Sumimoto Bakelite Co., Ltd.; Sumitomo Chemical Co., Ltd.; and Toyo Ink MFG Co., Ltd.

\section{Prof. Shiro Kobayashi \\ Department of Materials Chemistry Graduate School of Engineering Kyoto University Kyoto, Japan}

\section{Macromolecular Symposia, Vol. 158: Rheology of Polymer Systems. Symposium Editor, Jaroslav Kahovec; Editor, I. Meisel; Associate Editor, S. Spiegel; Assistant Editors, H. Beattie and C. S. Kniep. Published by Wiley-VCH, August 2000, pp. 1-182. ISBN 3-527-30137-6 (ISSN 1022-1360).}

Rheology of polymer systems in the molten state is an area of great scientific interest and practical importance. Molten polymer systems have fascinating rheological properties, which qualitatively differ from those of lowmolecular weight liquids. Knowledge of the properties and understanding of their relations to the structure are necessary conditions for efficient processing of polymeric materials. Microrheological description of the phase structure formation in multicomponent polymer systems during their preparation by melt mixing and processing is needed for controlling their structure and, therefore, also their properties. For these reasons, in the last decade, the rheology of polymer systems has been an object of intensive studies. Owing to the complexity of studied problems, correct determination of rheological properties of polymer systems is not always easy, and many various approximations are used in the description of the rheological behavior or polymer systems. Therefore, the discussion of methods of measurements, as well as plausibility and consequences of vari- 
ous approaches to the description of rheological properties and their relation to the structure of polymer systems, is extremely important.

Rheology of polymer systems was also the topic of the $19^{\text {th }}$ Discussion Conference organized as the $58^{\text {th }}$ meeting in the series of Prague Meetings on Macromolecules (PMM) on 19-22 July 1999 (see conference report by Dr. H. M. Laun published in Chemistry International in January 2000, Vol. 22, No. 1, p. 20). As usual, the meeting was held under the auspices of IUPAC at the Institute of Macromolecular Chemistry of the Academy of Sciences of the Czech Republic in Prague. A total of 66 participants from 22 countries contributed to the scientific program of the conference. There were 6 main lectures, 17 special lectures, and 23 poster communications. The most interesting panel discussions were devoted to problems of rheometry and processing in multiphase polymer systems (led by A. Ya. Malkin, Russia) and problems of the description of structure formation and evolution in molten multiphase polymer systems (led by J. Lyngae-Jørgensen, Denmark). All the contributions and discussions were very helpful for better understanding the problems of determination of rheological properties, of the prediction of relations between the structure and rheological properties of polymer systems, and of the description of the phase structure formation and evolution in multicomponent polymer systems. We believe that the main and special lectures collected in this volume will provide the same benefit to the readers.

The participants created not only an excellent professional forum, but also a very agreeable company. We wish to express our gratitude to all participants and sponsors for supporting the meeting, to the organizing committee for their very good job, and to the contributors for their carefully prepared papers.

\section{Dr. Ivan Fortelný and Dr. Jaroslav Kahovec Institute of Macromolecular Chemistry Academy of Sciences of the Czech Republic, Prague}

\section{Awards and Prizes}

\section{CNC/IUPAC Travel Awards Announced}

This article is paraphrased from the May 2000 issue of Canadian Chemical News (Vol. 52, No. 5, pp. 20-21).

The Canadian National Committee for IUPAC (CNC/IUPAC) established a program of Travel Awards in 1982. These awards are financed by the Gendron Fund (administered by the Canadian Society for Chemistry, CSC), supplemented by funds donated by $\mathrm{CNC}$ / IUPAC's Company Associates. The purpose of the awards is to help young Canadian chemists and chemical engineers (within 10 years of gaining their Ph.Ds) present a paper at an IUPAC-sponsored conference outside continental North America. Typically, six or seven awards of CAD 1 000-1 500 are made each year.

Winners of the 2000 CNC/IUPAC Travel Awards are
Manuel A. S. Aquino, St. Francis Xavier University, Antigonish, NS (34 ${ }^{\text {th }}$ International Conference on Coordination Chemistry, 34-ICCC, 9-14 July 2000, Edinburgh, Scotland, UK); Heinz-Bernhard Kraatz, University of Saskatchewan, Saskatoon, SK (34-ICCC); Glen R. Loppnow, University of Alberta, Edmonton, AB (18 ${ }^{\text {th }}$ IUPAC Symposium on Photochemistry, 2227 July 2000, Dresden, Germany); Susannah Scott, University of Ottawa, Ottawa, ON (34-ICCC); Brian D. Wagner, University of Prince Edward Island, Charlottetown, PE (18 ${ }^{\text {th }}$ IUPAC Symposium on Photochemistry); Steve A. Westcott, Mount Allison University, Sackville, NB; and Mark S. Workentin, University of Western Ontario, London, ON (18 ${ }^{\text {th }}$ IUPAC Symposium on Photochemistry).

\section{Reports from Commissions and Division Committees}

\section{Physical Chemistry Division Committee}

\section{Summary of Minutes of Commission Meeting at Wageningen, Netherlands, 1-2 April 2000}

The Physical Chemistry Division Committee met in April to review ongoing activities and to discuss how the Division can adapt to the new regime with drastically changed obligations for the Committee. The suggestion to the Secretary General in October 1999, that a half-time Scientific Liaison Officer should be assigned to the Division had not met with any enthusiasm. However, the Division President and Vice President will continue their efforts to acquire administrative support.

A tentative set of procedures and criteria for the review of new project proposals, prepared by the Division President, will be used on a provisional basis until adopted in some form at the IUPAC General Assembly in Brisbane, Australia in 2001.

The Committee is of the opinion that IUPAC needs to be more active in the field of databases, as there are 